\title{
The Path Choice of the Localization Course of MOOC in Chinese Colleges and Universities in the View of the Disputes behind the MOOC
}

\author{
Yong Liu \\ Personnel Department, China West Normal University, Nanchong, China \\ Email: liuyong007688@126.com
}

Received 23 July 2016; accepted 19 August 2016; published 22 August 2016

Copyright (C) 2016 by author and Scientific Research Publishing Inc.

This work is licensed under the Creative Commons Attribution International License (CC BY). http://creativecommons.org/licenses/by/4.0/

\section{(c) (i) Open Access}

\begin{abstract}
The birth of MOOC in 2012 caters to the long-standing appeal of administrators about teaching reform in world famous universities, and all colleges and universities have launched the MOOC. After several years of MOOC fanaticism, disputes about MOOC such as the cultural erosion tendency of MOOC, the security of MOOC big data, the effectiveness of MOOC teaching, appeared. From above disputes, highlighting the guiding role of national culture, paying attention to protect the security of MOOC big data, implementing national, social and school collaborative innovation in practice have become an inevitable path choice in the localization course of MOOC in Chinese colleges and universities.
\end{abstract}

\section{Keywords}

MOOC, Dispute, Localization, Path

\section{Introduction}

Since 2012, MOOC has become the world's most popular vocabulary in the field of education, and the New York Times calls 2012 the year of the MOOC. Famous universities in the world have raised banner of teaching reform, and established the independent MOOC platform or cooperated with MOOC platform providers, rolling out all sorts of MOOC to meet the global explosive learning demand of MOOC learners. There are many supporters of the revolution of the paradigm of MOOC in global higher education field, but after several years of MOOC fanaticism, more and more disputes about MOOC have began to attract people's attention. The objective 
of this paper is to analyze the disputes behind the MOOC, and to provide some useful paths for the localization of MOOC in Chinese colleges and universities, such as highlighting the guiding role of national culture in the localization course of MOOC in colleges and universities, paying attention to protect the security of MOOC big data, and implementing national, social and school collaborative innovation in practice.

\section{Disputes behind the MOOC}

\subsection{Cultural Erosion Tendency of MOOC}

Educational sovereignty, as well as economic sovereignty, political sovereignty, cultural sovereignty and informational sovereignty, is a lower concept of the national sovereignty. Economic sovereignty has always been of concern, and the importance of educational sovereignty has often been ignored. Educational sovereignty is a logical extension of the state sovereignty and cultural sovereignty [1]. Educational institutions are the core sites of shaping the national personality, and the essence of safeguarding the educational sovereignty is the maintenance of the right to the national education discourse and the national mainstream ideology and cultural values. Western countries through ideological penetration to influence the sovereignty of education in developing countries, including the traditional way: introducing teaching materials and curriculum content with western ideology into the school by foreign-owned and joint venture; through the acceptance of students and teachers to visit the culture of western democracy and political philosophy, especially focus on the training of a large number of "future leaders of developing countries by sending experts; scholars to developing academic exchanges to spread western values, such as Ford and the Fulbright Program"; through the world academic evaluation system of the value orientation of higher education policy in developing countries with subtle influence, such as QS university rankings, ESI research evaluation, Nature index. As a strong promoter and the internationalization of higher education, MOOC may become a new hidden leakage tool of education sovereignty, which cannot but arouse our vigilance.

When China joined the world trade organization, it does not make promises on cross-border delivery in the past has played a strong shielding effect, to some extent it may block out the harmful products to the sovereignty of education service, then in MOOC conditions, the shielding has been part of the digestion. As a matter of fact, Chinese students are free to take the foreign universities' MOOC is not a problem, Chinese colleges and universities initiative to join all kinds of foreign MOOC platform is not new, some of China's Internet companies take the initiative to provide MOOC products and services has become quite common. From an observed phenomenon, MOOC has become a new implicit infiltration education sovereignty tool, which not only a direct challenge to China's sovereignty of curriculum content, but also indirect spread of western ideology, as well as through the MOOC learning group to implement cultural infiltration.

Education is the transmission instrumental and expressive form of culture, and also is the core part of culture. The United States, by virtue of its innovative edge and the dominant position of the information industry, it pays homage to the world the biggest information suzerain and new culture colonial ruler. All the founders of Udacity, Coursera, and edX MOOC platform are the United States Universities. At the end of May 2016, Coursera has over 1000 courses, these courses covers almost all of the subjects of human civilization. In the humanities and social sciences, many wonderful courses, there is no lack of ideological penetration and harm to the national education sovereignty case. For example, the Harvard University social psychology courses content, it provides the introduction to classical and contemporary social psychology. It covers topics including decision, beliefs, group behavior, and personal charm, promote health and well-being. Harvard course, such as China, from history, geography, philosophy, literature, politics, economy, art, ecology, etc. point of view about China's past, now and future, but carefully read the content of the course, to China is basically smattering, even use the United States world view, values to judge China's development, such courses for students worldwide open may mislead the national image of China in the world.

Therefore, in order to understand the essence and practical utility of MOOC, when introducing MOOC into the university classroom, must of course "takes its essence, goes to its dregs", otherwise may lose the cultural habits of thinking and teaching methods in imperceptible in, and then completely become a vassal of the western culture.

\subsection{The Security of MOOC Big Data}

In the era of big data, the value of data as information assets has become more and more prominent. As a kind of 
important political and strategic resources, more and more attention has been paid to the countries all over the world. With the global promotion and application of the MOOC platform, the participation of hundreds of schools in the world and tens of millions of internet users, resulting in a lot of online teaching and user attribute data, the value of these data is immeasurable, even the data sovereignty is more involved. As the course of the network and globalization, such as Google earth software, MOOC brings rich and convenient information to the user, it also means that the development of global education is real-time monitoring and completely transparent at the same time. Cornell University opened in EDX platform < eavesdropping big data: era of Internet privacy and monitor > curriculum is a typical case, it is proved that the rapid development of big data and cloud computing technology has been able to let network data association become the key information to crack the password.

Therefore, the maintenance of our country's MOOC data security, should fully consider the potential value of MOOC data, and strive to build our own characteristics of MOOC platform, to avoid excessive dependence on foreign products. In this aspect, some colleges and universities in China has made a useful attempt, such as Tsinghua University in 2013 launched the first MOOC platform XuetangX, followed by Peking University, Fudan University, Shanghai Jiao Tong University, which have launched their own MOOC platforms. How to deal with the contradiction between globalization and localization of MOOC construction, it is necessary to continue to promote the internationalization of curriculum, but also pay attention to protect data sovereignty. The security of MOOC big data is another major controversy.

\subsection{Teaching Effectiveness of MOOC}

\subsubsection{Dropout Rate of MOOC}

Meyer (2012) research report pointed out that Stanford, Massachusetts Institute of technology and University of California at Berkeley, the school dropout rate is between $80 \%-95 \%$. For example, 50,000 students enrolled in software engineering course of the University of California at Berkeley, only $7 \%$ of the students completed the entire MOOC. Only $2 \%$ of the students complete the social network analysis course in Coursera platform, $0.17 \%$ of the students have achieved excellent certificate and obtain the basis of badges [2]. As is known to all, all the countries in the world have higher education quality assurance mechanism, on one hand are to ensure the value of the public capital investment, on the other hand is to ensure that students receive a good education. Course completion rate and degree of access rate are the standards of quality audit and evaluation personnel. To reduce the loss of students and to improve the graduation rate of students has been subject to the attention of distance education institutions and open universities.

Katy Jordan researched the most popular $29 \mathrm{MOOC}$ in Udacity, Coursera and edX platforms, found that the average number of registered for each course is about 43,000 students, about $6.8 \%$ of the students complete the courses, if the number of students who finish part of the course are included, complete rate rose to about $9.8 \%$. At the same time, she found that whether to insist on the completion of a certain course related with the duration of the MOOC, that is to say, the students choose MOOC is not entirely affected by the fame of schools and professors [3]. According to the vast majority of research literature, so far, this ratio is mostly below $10 \%$, with a median of about $6.5 \%$ [4]. Researchers believe that the dropout rate is not important, if the purpose is to allow the public to participate in the course of the University of brand-name university courses and major courses, the high dropout rate does not have to make a fuss.

\subsubsection{Credit Certification of MOOC}

More controversial is the credit and certification issues. So far, most of the MOOC platforms for students who successfully pass the course exam only to provide certificates, rather than credits, the students only complete the entire learning process can get the badges or proof of courses completion. Despite the latest trend is that more and more universities began to recognize and accept the MOOC credits, because this move is conducive to the promotion of the school's marketing and awareness, and thus bring more students to register their courses [5]. However, according to the survey data, $72 \%$ of the MOOC teachers regard that it should not be given MOOC credits [6]. However, the American Council on education have been proposed to give credits to five MOOC on Coursera platform. The chairman Molly Corbett broad regards that as long as MOOC teachers fully assess the content of the course, the proper application of the teaching method, learners fully participate in and complete the activities and requirements of various courses, MOOC and the same courses with traditional forms in university should not be discriminated. However, Touve (2012) has a positive view of the MOOC credits, he be- 
lieves that whether students can get a degree depends on the university admissions process rather than the students to grasp the appropriate curriculum knowledge. This is a very absurd idea, taking the open-university in the UK as an example, with no entry requirements but so far has been awarded more than one million copies of genuine and acclaimed diploma, which is a good practice of the easy entrance and hard graduation.

\subsubsection{Teaching Evaluation of MOOC}

Suen (2014) believes that the teaching without testing whether learners have acquired the appropriate knowledge and feedback the results of the evaluation is equivalent to the dumping of information in a single direction or radio broadcasting, rather than education. Without evaluation and feedback of the MOOC have no difference with the thousands of free videos on internet or videos available on Khan Academy [7]. At present, MOOC mainly uses the online automatic scoring brief choice learning as evaluation tools, only a handful of MOOC take the open short answer questions as test method, but taking into account the number of learners, it is difficult to imagine a MOOC teachers have time and energy to It is hard to imagine a mu class teachers have the time and energy to review such amount of homework. Therefore, MOOC often rely on peer assessment way to do learning measurement, such as Coursera and Udacity platform. There is a dispute over this issue. There are teachers and researchers believe that this led to the proliferation of plagiarism and cheating, and a large number of MOOC learners make this problem even more serious. Generally speaking, the ideal learning evidence is that students are able to produce independent thought or specific results, for example, can answer open questions, independently write insightful articles or reports, design specific product, and optimize the process of a project or solve ill structured complex problem, and MOOC learning evaluation is generally ask learners to complete some automatic scoring of online objective multiple-choice questions according to the requirements of each MOOC unit. The subject is mainly used to measure the mastery degree of the learners' concept of the unit and other content, test scores show that learners have fully learn and master the teaching content. In addition, the system requires the low scores learners to review the previous unit content. In addition, the design of the high quality of the choice questions to evaluate the learner's analysis, synthesis and evaluation of the ability for most of the MOOC teachers is also a huge challenge.

Another widely used evaluation methods is the peer assessment. The research on the evaluation method is very extensive and in-depth, but the process of peer review what the researchers studied is traditional classroom teaching, and the method is generally in the teacher's guidance and supervision, and finally teacher will comment it. However, MOOC is completely different from the traditional classroom teaching, the effectiveness of peer assessment is questioned by many researchers and it caused great controversy. First, hundreds of thousands of learners to evaluate the million home works, which involve the assignment of which is very complex. Secondly, MOOC students' mutual evaluation almost without teacher participation, guidance or supervision, assessment, obviously the quality of evaluation cannot be guaranteed. Finally, MOOC learners tend to be distributed around the world, language, culture, values and world views are different from each other, as without teacher's guidance and supervision, maybe the learners will be lack of sense of responsibility or effective incentive, so they are difficult to seriously treat other students' homework. However, the greatest controversy is the credibility of the evaluation results; even before the assessment, the learner has received the appropriate job standard training, it cannot completely rule out the false judge to high quality homework.

\section{The Urgency of the Localization of Chinese MOOC}

The most significant value implied in the MOOC is a very deep and intense game between the world famous universities. In the new space and time of the MOOC curriculum, Harvard, Stanford and other American universities are not just showing their courses. What is the course? It is culture, ideology, and national spirit. Famous university is a national and ethnic culture pagoda tip, and is the elites of the Cultural Palace, here is full of strong national pride and mission sense. MOOC build an open high-end cultural exchanges arena. In the past, the exchange of universities mainly showed the principal, the professor and the students' mutual visits. Today, different cultural education dialogue, communication, and game start online, and appeared in basic course of college teaching activities. The challenge for China is not just limited to the higher education, but a big problem related to the national culture of vital importance.

The change in the education field is causing a worldwide collision of ideas and concepts. Currently debates surrounding the MOOC rage on. Supporters called it a tsunami of higher education, subversive innovation; op- 
ponents called it another speculation and bubble in internet industry. Every time a profound educational reform comes, and it is bound to be accompanied by fierce ideological confrontation. There are a lot of problems about MOOC, but it cannot be denied their value. The spirit of university culture game is more important than the ideological argument. On the stage of MOOC, the vision, personality, image of Chinese professor, and the cultural heritage and innovation strength of Chinese University will be displayed on this stage. Whether China can show the ideological and cultural spirit in influence of human civilization in the 21 st century? This should be the president of the University of China, professors, and all levels Chinese decision makers' cultural consciousness and mission of the times. Therefore, the localization of the construction of the Chinese MOOC demand is particularly urgent.

\section{The Path Choice of the Localization Course of MOOC in Chinese Colleges and Universities}

The educational ideal of MOOC for global citizens is to share quality education resources; its major mission is to promote the first-class education to all corners of the world, and even every village on the African land. Practice the global education concept, so that the global students get equal education opportunities. From the date of birth, MOOC has insisted on its openness from beginning to end, to achieve equality of educational starting point, to share the global quality educational resources, and to realize the equality of educational resources. From this point of view, MOOC does contribute to the realization of educational equity, promote education and democracy. Therefore, the localization of MOOC in Chinese colleges and universities can follow the following path.

\subsection{Highlighting the Guiding Role of National Culture in the Localization Course of MOOC in Colleges and Universities}

From the current situation, the development of MOOC has an irreversible trend and the influence of MOOC on higher education is unavoidable problem. The globalization development of MOOC will inevitably bring about the conflict between different cultures and ideologies and integration. This requires taking MOOC into the national cultural security, information security education, ideological security, even in the vision of political stability and safety to study. We should carry forward the unique charm of Chinese culture through MOOC, let more people all over the world understand China, improve China's higher education in the discourse of higher education all over the world. Therefore, the Chinese MOOC in the process of localization should adhere to the education, technology, business and security perspective [8]. In the perspective of education, mainly take the research of MOOC and education reform, this reform involves the global competition of higher education and even basic education. In the perspective of technique, mainly take the research of technology support platform for research and development, and the need for a wide range of relevant technical fields experts and scholars, not only educational technology. In the perspective of business, mainly take the research of Chinese MOOC platform business model, to provide a solid foundation for the development of Chinese style MOOC, which requires the economic field of theorists and practitioners to join. In the perspective of security, mainly take the research of the penetration of the ideological education and the western countries, and the ideological education reform and development under the background of MOOC.

\subsection{Paying Attention to Protect the Security of MOOC Big Data}

The essence of big data is tracking and collecting individual data in a long-term, through analyzing the stock of the data and providing intelligent and personalized service. On September 5, 2015, the State Council issued on promoting the development of large data of the platform for action, which aims at promoting the sharing of government data and opening up public data resources, and striving to 2018 complete the establishment of national data unified and open platform, and accelerating the construction of data for a powerful country. In the teaching process of MOOC, a large number of online teaching data and user attribute data produced, and some association between the data may even become the key information to crack the password. Therefore, in the localization process of Chinese MOOC the localization of MOOC platform is the first one. In the globalization and localization process of MOOC, we should not only continue to promote the internationalization process of Chinese MOOC curriculum, but also pay attention to protect the safety of big data of MOOC. 


\subsection{Implementing National, Social and School Collaborative Innovation in Practice}

MOOC is not only a theoretical problem, but also a practical problem. The rise of MOOC in the United States, on the surface is the advocate and practice of individual teacher, but the essence is the government and enterprises jointly promoting it, even the government play a key role and behind a vigorously spread purpose of American culture. We will strengthen the theoretical study of MOOC, and we should attach great importance to the practice of MOOC innovation at the same time. First of all, in the national level we should take MOOC issues into the national political security, and raise it to the national strategic issues level. Form relevant institutions timely to strengthen the research and practice of top-level design, full support and promotion. Secondly, in the social level, MOOC development need the joint efforts of the whole society, especially the relevant enterprises, from the perspective of business interests and social responsibility, and actively participate in research and practice of the MOOC, provide the impetus for the sustainable development of Chinese MOOC. Finally, in the school level, we will connect the development of MOOC and the reform of education and teaching in new period, especially in colleges and universities, we should have the courage to bear the main responsibility, research and develop international first-class MOOC platform. Through the active practice of MOOC in Chinese colleges and universities, we should achieve the collaborative innovation of country, social and school.

\section{Conclusion}

This paper provides some useful paths for the localization of MOOC in Chinese colleges and universities by analyzing the disputes behind MOOC, such as highlighting the guiding role of national culture in the localization course of MOOC in colleges and universities, paying attention to protect the security of MOOC big data, and implementing national, social and school collaborative innovation in practice.

\section{Funding}

This paper is one of the achievements of the project funded by Sichuan Province Education Development Research Center, and the project number is CJF15053.

\section{References}

[1] Liang, J.-S. (2008) National Sovereignty and Educational Sovereignty. Academic Research, 1, 92-93.

[2] Weller, M. (2015) Amnesi MOOC. Blog the Ed Techie, June 13. http://nogoodreason.typepad.co.uk/no good reason/MOOC/

[3] Jordan, K. (2014) Initial Trends in Enrolment and Completion of Massive Open Online Courses Massive Open Online Courses. International Review of Research in Open and Distance Learning, 15, 133-160.

[4] Ferenstein, G. (2014) Study: Massive Online Courses Enroll an Average of 43,000 Students, 10\% Completion. http://techcrunch.com/2014/03/03/study-massive-online-courses-enroll-an-average-of-43000-students-10-completion/

[5] Carey, K. (2014) Into the Future with MOOC's. The Chronicle of Higher Education. http://chronicle.com/article/Into-the-Future-With-MOOCs/134080

[6] Young, J.R. (2014) American Council on Education May Recommend Some Coursera Offerings for College Credit. The Chronicle of Higher Education. http://chronicle.com/article/American-Council-on-Education /135750/

[7] Suen, H.K. (2014) Peer Assessment for Massive Open Online Courses (MOOCs). IRRODL, 15, 12-327.

[8] Li, Y.-Y. (2015) Review of the Current Research Situation of MOOC in China: Hot Spot and Trend. e-Education Research, 7, 55-60. 


\section{Submit or recommend next manuscript to SCIRP and we will provide best service for you:}

Accepting pre-submission inquiries through Email, Facebook, LinkedIn, Twitter, etc.

A wide selection of journals (inclusive of 9 subjects, more than 200 journals)

Providing 24-hour high-quality service

User-friendly online submission system

Fair and swift peer-review system

Efficient typesetting and proofreading procedure

Display of the result of downloads and visits, as well as the number of cited articles

Maximum dissemination of your research work

Submit your manuscript at: http://papersubmission.scirp.org/ 